DOI: https://doi.org/10.30749/2177-8337.v23n46p65-76

\title{
REVOLUÇÃO 4.0 NO PODER JUDICIÁRIO: LEVANTAMENTO DO USO DE INTELIGÊNCIA ARTIFICIAL NOS TRIBUNAIS BRASILEIROS
}

\section{REVOLUTION 4.0 IN JUDICIAL POWER: MAPING THE USE OF ARTIFICIAL INTELIGENCE IN BRAZILIAN COURTS}

Fernanda Bragança* Laurinda Fátima da F. P. G. Bragança**

Resumo: Este artigo tem por objetivo fazer um levantamento do uso de inteligência artificial pelo Judiciário brasileiro de modo a identificar os tribunais em que a mesma já está implantada e as funções que realiza. Os portais institucionais e alguns sites especializados divulgam notícias esparsas sobre esta temática, mas a necessidade de constante atualização dificulta a elaboração de estudos sistematizados. Esta pesquisa visa contribuir com algumas informações mais detalhadas sobre a realidade tecnológica de alguns órgãos judiciários do país e sobre o que se pode esperar para um futuro próximo neste campo. A metodologia consistiu em uma revisão bibliográfica de artigos que abordaram este assunto.

Palavras-chaves: Inteligência artificial. Poder Judiciário. Processo decisório.

Abstract: The objective of this article is to map the use of artificial inteligence by Brazilian Judiciary, identifying the courts where it is already estabilished and the functions it performs. Institutional portals and some specialized websites spread sparse news on this subject despite the constant need for updating, hindering the elaboration of systematic studies. The present research aims to provide more detailed and consistent information about the technological reality in some judicial organs in the country and what can be expected on this subject in the near future. The methodology consisted in a bibliographic review of articles on this subject.

Keywords: Artificial intelligence. Judicial power. Decision making.

\footnotetext{
* Doutoranda no Programa de Sociologia e Direito da Universidade Federal Fluminense - UFF. Mestre em Direito pela Universidade Federal do Rio de Janeiro - UFRJ/FND. Bacharel em Direito pela Universidade Federal do Rio de Janeiro - UFRJ/FND. Pesquisadora do Laboratório Fluminense de Estudos Processuais - LAFEP.

** Doutora pela Pontifícia Universidade Católica do Rio de Janeiro - PUC-Rio. Professora da Universidade Federal Fluminense- UFF.
} 


\section{INTRODUÇÃO}

O tema desta pesquisa é o uso da inteligência artificial pelo Poder Judiciário brasileiro. O movimento mais recente de modernização deste órgão está impulsionado pelo uso da mesma e a todo momento surgem notícias de projetos e emprego de novas tecnologias em algum tribunal do país. Diante deste contexto, esta investigação tem dois objetivos principais: identificar quais os órgãos judiciários usam I.A. nas suas atividades e verificar quais tarefas a mesma desempenha. A proposta é, portanto, fazer um mapeamento abrangente a partir das experiências registradas e divulgadas pelas Cortes de Justiça.

Esta pesquisa busca enfrentar as seguintes indagações: em quais Cortes de Justiça do Brasil a inteligência artificial está sendo empregada e como se dá o seu funcionamento? Apesar de ser um assunto pujante na atualidade, as informações institucionais esparsas veiculadas pelas assessorias de comunicação dos tribunais não permitem uma verificação concreta de quais trabalhos a I.A. vem desempenhando. Somente através de um levantamento criterioso será possível visualizar o nível de avanço tecnológico que há no país no âmbito judicial.

A metodologia de estudo consiste em uma revisão bibliográfica de artigos científicos que tratam sobre esta temática na esfera do Judiciário e que contribuam com algum exemplo, referência ou análise de caso sobre um ou mais sistemas de I.A. já implantados pela Justiça brasileira.

\section{NOÇõES PRELIMINARES SOBRE A INTELIGÊNCIA ARTIFICIAL}

A inteligência artificial vem se tornando cada vez mais presente nas operações casuais do dia a dia, como no reconhecimento facial para desbloquear o aparelho celular, na personalização de ofertas de produtos e anúncios a partir de uma busca realizada na internet, no comando de voz para mudança de uma estação de rádio no veículo. Estamos mais conectados e interagimos com uma frequência crescente com as assistentes virtuais dos smartphones como a Siri, por exemplo.

Toda essa conectividade facilita e agiliza a vida das pessoas, a produtividade aumenta e um número progressivamente maior de tarefas consegue ser 
desempenhado com apoio desses recursos tecnológicos. Esta interatividade chegou também no âmbito do Poder Judiciário, que atualmente, já conta com a ajuda de robôs para algumas atividades. A I.A. encontra-se inserida, inclusive, no próprio processo decisional.

Em uma análise retrospectiva, a I.A. no Direito por muito tempo se restringiu à edição de textos e construção de planilhas de dados. No início da década, o tratamento dessas informações era bastante incipiente e poucas ferramentas estavam disponíveis. Com os anos, esta tecnologia começou a ser inserida nos grandes escritórios de advocacia e trouxe avanços na classificação e gestão dos processos.

A partir do ano de 2016, começou-se a evidenciar uma mudança mais robusta na utilização da I.A., que pode ser explicada pela diminuição do custo de armazenamento e aumento da capacidade de processamento de dados. Com a explosão das startups, inclusive no setor jurídico, o ambiente tornou-se fortemente digitalizado e propício ao tratamento de informações de massa. (COELHO, 2019).

Foi neste cenário que a I.A. encontrou um contexto favorável para colocar em prática toda a sua potencialidade, tanto para a organização de dados não estruturados quanto para as correlações e sugestões voltadas à tomada de decisão.

Atualmente, o que existe de mais avançado e que está sendo empregado no contencioso de alguns escritórios de advocacia não está relacionado à formulação de petições, como facilmente se poderia cogitar. Isto pode ser feito por simples recursos de automação. Hoje, o que há de mais sofisticado são os softwares que melhoram a pesquisa jurídica, identificam o assunto, as parte e os pedidos do processo e separam as decisões de maneira a facilitar o trabalho dos advogados, promotores e juízes. (COELHO, 2019).

O primeiro momento da onda de utilização deste tipo de tecnologia foi marcado pela sua proliferação por todos os campos e a interatividade passou a ser sinônimo de modernidade e melhor desempenho. Mais recentemente, essa empolgação deu lugar à uma preocupação com o mapeamento de informações pessoais e acesso à vida privada. Com relação às decisões judiciais, esta mudança de percepção é ainda mais sensível, tendo em vista a complexidade inerente ao próprio ofício: decidir sobre a vida de uma pessoa. 
O uso da inteligência artificial pelo Poder Judiciário na sua atividade típica ganhou tanto destaque que passou a ser debatido em diversos seminários e fóruns sediados nas próprias escolas de magistratura. Ainda assim, há muito pouca clareza quanto a aspectos elementares dessa temática, em que pese a manifesta curiosidade e disponibilidade desses servidores em tentar entender o que acontece nas máquinas para que emitam uma determinada decisão.

O perigo dessa falta de conhecimento sobre o funcionamento dessas tecnologias é que este conteúdo é a base para todas as outras discussões que envolvem as suas repercussões e faz com que as avaliações dos riscos do seu uso e do impacto sobre os profissionais da área ${ }^{1}$ fiquem extremamente prejudicadas, por exemplo. (KUZNIETEZ, 2018).

A definição sobre o que consiste a I.A. é uma tarefa bastante desafiadora. Ela está inserida em um campo vasto e interage com vários ramos do conhecimento que vão muito além das áreas técnicas e da computação. À grosso modo, a fabricação de uma I.A. visa à imitação do processo cognitivo do ser humano. A expansão recente do seu uso se explica, sobretudo, pelo progresso no "aprendizado" das máquinas.

De modo geral, a I.A. diz respeito à programação de computadores para três principais finalidades: aprendizagem, percepção e planejamento, que são características da inteligência humana. Trata-se de um modelo computacional em que os programadores inserem os dados pertinentes de modo que, com o tempo, esta tecnologia é capaz de elaborar os próprios resultados. Através de um mecanismo conhecido como machine learning, a máquina aprende com as informações colocadas por humanos e a partir daí desenvolve sua própria capacidade

\footnotetext{
${ }^{1}$ É possível citar pelo menos três impactos do uso de novas tecnologias, incluindo I.A. para os profissionais da área jurídica, que variam conforme o momento profissional de cada um:

- Para os recém-formados em direito, o treinamento e o desenvolvimento de habilidades e talentos estão cada vez mais focados em áreas de maior valor agregado, ficando em um segundo plano as operações mecânicas, de memória ou meramente administrativas.

- Para os profissionais do direito na procura de oportunidades de crescimento, é essencial a compreensão e o gerenciamento de novas tecnologias disponíveis, de forma que estas contribuam para a melhoria da sua produtividade e não sejam uma tentação para sua substituição.

- Para aqueles que lideram equipes de advogados em escritório ou diretorias jurídicas de empresas, é fundamental o desenvolvimento de uma estratégia clara que permita incorporar tecnologias, mantendo um equilíbrio entre eficiência, produtividade e talento.
} 
cognitiva e decisória. À grosso modo, ela assimila como "pensar" de forma racional e autônoma diante de uma determinada situação.

Um sistema programado para utilizar a I.A. tem a capacidade de decidir, dentre as opções pré-estabelecidas, a que melhor se adequa ao caso. Isto é possível graças a um banco de dados constantemente abastecido por novas informações pela própria máquina, as quais são captadas a partir das referências programadas inicialmente pelo desenvolvedor.

Neste momento cabe frisar o seguinte ponto: quem define os dados a partir dos quais a I.A. irá fazer as suas análises é um indivíduo e, portanto, cabe a reflexão de que neste processo existe a possibilidade de que o mesmo desvirtue a máquina a reproduzir padrões discriminatórios que ele mesmo eventualmente possua, ainda que o faça de modo inconsciente.

Deste modo, fica claro que a constituição dos sistemas se faz a partir das preferências dos programadores ou dos adquirentes do produto e são reflexo das opiniões e prioridades desses sujeitos. A máquina, por conseguinte, não é inteiramente isenta, uma vez que depende de uma atividade humana preliminar de seleção de informações; o que gera uma preocupação quanto a esses desvios cognitivos.

O fato do sistema ser constituído por dados selecionados, por si só, não representa um problema. A questão é que se trata de uma situação desconhecida e que é agravada pela falta de transparência do funcionamento dos algoritmos ${ }^{2}$ que o compõe. O perigo é que tudo isso possa estar revestido de uma pretensa imparcialidade matemática quando na verdade é um mecanismo que provoca desajuste social.

Uma amostra prática da dimensão que pode alcançar este tipo de complicação é o Correctional Offender Management Profilling for Alternative Sanctions - COMPAS, um sistema que opera a partir de uma I.A. e que foi largamente utilizado nos EUA para avaliar o risco de reincidência dos criminosos do

\footnotetext{
${ }^{2}$ À grosso modo, o algoritmo corresponde à uma sequência de passos para a execução de uma tarefa que quando aplicados a um determinado conjunto de dados permite solucionar problemas semelhantes (AB2L, 2017). Em geral, uma grande quantidade de algoritmos compõe o sistema de inteligência artificial. Através do mecanismo de machine learning, por exemplo, os algoritmos aprendem automaticamente a partir de dados.
} 
país. No entanto, uma verificação realizada pelo organismo ProPublica constatou que o algoritmo era tendencioso em classificar réus negros como de maior reincidência que os brancos. $O$ agravante é que alguns estados norte-americanos se baseavam nesses resultados para determinar a pena do acusado e quanto maior o índice de reincidência, mais tempo de reclusão era cominado ao detento. (NUNES; MARQUES, 2018, p. 6). Em que pese esta experiência e outros exemplos no mesmo sentido, a reação não deve ser de medo da I.A. O esforço que precisa ser feito é de bem compreendê-la em toda a sua operação.

\section{A INTELIGÊNCIA ARTIFICIAL NO PODER JUDICIÁRIO BRASILEIRO}

A I.A. já uma realidade inclusive na mais alta Corte do Brasil. O Supremo Tribunal Federal tem o seu próprio projeto, que foi apelidado de Victor e desenvolvido em parceria com a Universidade de Brasília a um custo de aproximadamente um milhão e meio de reais. A previsão é que esteja operando na sua plena capacidade ainda neste ano de 2019. Esta cooperação com o meio universitário irá produzir inúmeras pesquisas de ponta no país que assumirá finalmente um destaque nas discussões sobre inovação. A estimativa é que os recursos investidos já foram totalmente recuperados. (TEIXEIRA, 2018).

A iniciativa foi nomeada em homenagem ao ex-ministro do STF Victor Nunes Leal, que foi o primeiro magistrado da Instituição que teve uma postura ativa na sistematização dos precedentes do Tribunal de modo a facilitar o reconhecimento dos assuntos mais frequentes.

Essa ferramenta é capaz de executar, por exemplo, a identificação dos recursos que se enquadram em um dos vinte e sete temas mais recorrentes de repercussão geral e a respectiva devolução aos tribunais de origem. Esta última pode ter por finalidade tanto a aplicação de uma tese já consagrada pelo STF quanto o sobrestamento de um processo enquanto aguarda o julgamento pelos ministros. (TEIXEIRA, 2018).

Além disso, Victor está habilitado para proceder à identificação e separação das cinco principais peças dos autos: acórdão recorrido, o juízo de admissibilidade do recurso extraordinário, petição do recurso extraordinário, sentença e agravo no 
recurso. Os servidores do núcleo de repercussão geral levavam em torno de trinta minutos para concluir este trabalho, enquanto que a I.A. demora apenas cinco segundos. (TEIXEIRA, 2018).

Devido à sobrecarga de trabalho em algumas varas, muitos processos sequer passavam por este tipo de triagem e eram enviados ao relator sem qualquer prévia identificação das peças. Agora, tudo chega devidamente separado; o que facilita bastante a elaboração do voto.

O Victor também converte de arquivos de imagem em texto e permite a edição de recursos de "copia e cola" de palavras ou trechos para outros documentos. Isto agiliza bastante a redação dos acórdãos com base no que consta nos autos. Se levada em consideração a elaboração de uma única decisão, pode parecer pouca economia de tempo, mas com um volume de escala, os ganhos com a celeridade passam a ser mais evidentes. O diretor-geral do STF, Eduardo Toledo, ressaltou, inclusive, que este projeto certamente contribuirá para fomentar o investimento em inovação no Judiciário.

De acordo com o portal institucional do STF, o Victor não se limitará ao seu objetivo inicial de aumentar a velocidade de tramitação dos processos por meio da utilização da tecnologia. $O$ que não quer significar, porém, que a máquina irá ocupar o lugar dos juízes. A mesma não decide ou julga; ela está sendo treinada tão somente para atuar na organização dos processos visando o aumento da eficiência e da velocidade da avaliação judicial.

Desde meados de 2018, o Superior Tribunal de Justiça está desenvolvendo o projeto Sócrates. Ele é capaz de fazer o reconhecimento de texto e classificar o processo por assunto antes mesmo da distribuição processual. Além disso, está sendo aprimorado para separar casos com controvérsias idênticas e localizar ações em que sejam aplicáveis os mesmos precedentes do tribunal. (CONSULTOR JURÍDICO, 2018).

A expectativa é que o Sócrates será finalmente testado em agosto de 2019 e espera-se uma redução de pelo menos $25 \%$ do tempo entre a distribuição e a primeira decisão em recurso especial. Em termos de produtividade, isso representaria um ganho de $10 \%$ nos processos julgados em relação ao volume protocolizado no mesmo período. (MIGALHAS, 2019). 
O Tribunal de Justiça do estado de Minas Gerais, através de sua diretoria de informática, projetou o Radar, uma I.A. com capacidade para identificar e separar recursos com pedidos idênticos. Após esta separação, os desembargadores elaboram um voto padrão a partir de teses das Cortes Superiores e do próprio TJMG, o qual é então utilizado pela máquina para proceder a julgamentos em conjunto dos casos similares. Na primeira oportunidade em que foi empregado, o Radar julgou de uma só vez duzentos e oitenta processos. (MINAS GERAIS, 2018).

O Tribunal de Justiça do Rio Grande do Norte também já usa ferramentas de I.A. para dar celeridade aos processos por meio do auxílio de três robôs batizados de Poti, Jerimum e Clara, todos em fase de testes. O Poti realiza automaticamente a busca e bloqueio de valores em contas bancárias em apenas trinta e cinco segundos ${ }^{3}$. Ele também é habilitado a atualizar o valor da ação de execução fiscal e transferir a quantia bloqueada para as contas oficiais indicadas no processo. A rapidez e a eficiência são tão impressionantes que provocou a extinção do setor que cuidava das penhoras na comarca de Natal.

O Jerimum, por sua vez, classifica e rotula processos enquanto Clara lê documentos e recomenda decisões semelhantes, como por exemplo, a extinção de uma execução quando o tributo já foi pago. Todos os três sistemas foram desenvolvidos em parceria com a Universidade Federal do RN. (BAETA, 2019).

O TJ de Rondônia seguiu nessa mesma linha e criou o Sinapse através de seu próprio núcleo de inteligência artificial. Uma das suas habilidades é o "módulo gabinete", que indica ao juiz as etapas seguintes do processo e o auxilia na elaboração de sentenças a partir de sugestões de frases. A Corte estadual de Pernambuco criou o Elis, que analisa uma certidão de dívida ativa, confere os dados, verifica a existência de prescrição e analisa a competência. Esta I.A. é direcionada a um setor de grande gargalo no Judiciário, a execução fiscal. (BAETA, 2019).

Em fevereiro de 2019, o Conselho Nacional de Justiça implantou o seu laboratório de inovação e um centro de I.A. voltado a atender ao Judiciário. A ideia é

\footnotetext{
${ }^{3}$ Graças ao robô Poti não é mais necessário que o servidor entre no sistema eletrônico do Banco Central, o Bacen Jud e solicite manualmente a busca e o bloqueio de valores em contas bancárias. Mesmo sem dinheiro em conta, o Poti pode ser programado para buscar o montante em períodos consecutivos de 15, 30 ou 60 dias.
} 
criar ferramentas, produzir pesquisas e comparar experiências que auxiliem os magistrados a decidir melhor, tornar mais célere os fluxos processuais e encerrar com mais rapidez os processos. Os focos são essencialmente automatizar as rotinas judiciais com o uso de robôs e usar I.A. para criar soluções de apoio às decisões dos juízes. (BAETA, 2019).

Uma grande preocupação do CNJ, atualmente, está voltada à questão dos sistemas dos diversos tribunais do país "conversarem" entre si. Essa funcionalidade é fundamental para a produção de métricas, diagnósticos e a longo prazo, a definição de políticas públicas. (SKAF, 2019).

Desde março de 2019, o Conselho da Justiça Federal investe no programa de desburocratização e simplificação que visa incentivar e captar práticas e casos de sucesso na Justiça Federal que facilitem procedimentos judiciais, extrajudiciais e de administração judicial. A iniciativa foi apelidada de FLUI JF e incentivou uma postura mais ativa por parte do órgão. Em junho, o CJF anunciou a criação de uma plataforma de inteligência artificial, a Lia, com o objetivo de responder dúvidas dos usuários por meio de um portal.

$\mathrm{Na}$ sua fase inicial de testes, o robô fará consultas à agenda funcional e responderá perguntas frequentes que são direcionadas à Ouvidoria. Segundo os desenvolvedores do sistema, a proposta é que o mesmo colete informações e gere novos dados, adaptando-se às necessidades do usuário. (BRASIL, 2019).

O Presidente do CJF e ministro do STJ, João Otávio de Noronha, já sinalizou o interesse em discutir um padrão de inteligência artificial que se adeque à realidade de todos os tribunais regionais federais e convocou para o mês de agosto uma reunião com servidores da área de tecnologia da informação. (BRASIL, 2019).

Essas iniciativas foram as pioneiras no país em termos de uso de I.A. pelo Judiciário. Pelo menos outros oito tribunais estão em vias de desenvolverem projetos de sistemas inteligentes como Acre, São Paulo, Alagoas, Ceará, Mato Grosso do Sul, Santa Catarina, Amazonas e Rio de Janeiro. Nas tabelas abaixo é possível verificar de uma forma mais sistematizada o que já está em operação no Brasil. 
Tabela 1 - Inteligência Artificial nos Tribunais brasileiros

\begin{tabular}{|c|c|c|c|c|c|c|}
\hline & TJMG & TJRN & TJRO & TJPE & STF & STJ \\
\hline Nome da & Radar & Poti, & Sinapse & Elias & Victor & Sócrates \\
\hline Inteligência & & Jerimum & & & & \\
\hline Artificial & & e Clara & & & & \\
\hline
\end{tabular}

Fonte: Autoras.

Tabela 2 - Inteligência Artificial nos demais órgãos judiciários

\begin{tabular}{|c|c|c|}
\hline & CJF & CNJ \\
\hline $\begin{array}{c}\text { Nome da Inteligência } \\
\text { Artificial }\end{array}$ & Lia & Laboratório de Inovação \\
\hline
\end{tabular}

Fonte: Autoras

\section{CONCLUSÃO}

A inteligência artificial é uma realidade em pelo menos seis tribunais do país, além de outros dois órgãos do Judiciário. Há ainda projetos em andamento para implementação em toda a Justiça federal e em outras oito Cortes estaduais. Neste momento, o uso de I.A. pela Justiça tem como principal objetivo conferir maior celeridade aos processos com a prolação mais rápida de decisões e as funções mais comuns são identificação de peças e separação dos casos por assunto. Os sistemas mais sofisticados auxiliam na elaboração de textos e preparação de sentenças.

A região Nordeste é a que mais faz uso de I.A. no seu sistema judiciário e algumas dessas tecnologias resultaram de parcerias com universidades; o que gera investimento, fomenta a pesquisa acadêmica e desenvolve o empreendedorismo universitário por parte tanto dos docentes pesquisadores quanto dos próprios alunos.

Uma iniciativa das mais expressivas foi a construção de um laboratório de inovação pelo CNJ que tem como uma das suas metas fazer com que os sistemas que estão em operação interajam entre si de maneira a possibilitar uma maior troca de informações, bem como ampliar a produção de estatísticas e o conhecimento sobre o contexto judicial. 


\section{REFERÊNCIAS}

BAETA, Zínia. Tribunais investem em robôs para reduzir volume de ações. Jornal Valor Econômico, legislação, São Paulo, 18 mer. 2019. Disponível em:https://www.valor.com.br/legislacao/6164599/tribunais-investem-em-robos-parareduzir-volume-de-acoes. Acesso em: 6 ago. 2019.

COELHO, Alexandre Zavaglia. A ciência de dados e a inteligência artificial no Direito em 2018 - Parte I. Conjur, [S.I.], 1 jan. 2019. Disponível em: https://www.conjur.com.br/2019-jan-01/zavaglia-ciencia-dados-inteligencia-artificialdireito. Acesso em: 12 ago. 2019.

KUZNIETEZ, Gabriel. Inteligência artificial no Direito chegou para ficar. Jota, tecnologia, coluna do Demarest, 5 dez. 2018. Disponível em: https://www.jota.info/opiniao-e-analise/colunas/coluna-do-demarest/inteligenciaartificial-no-direito-chegou-para-ficar-05122018. Acesso em: 12 ago. 2019.

BRASIL. Justiça Federal. Na era da Inteligência artificial, Conselho da Justiça federal lança plataforma que interage com usuários no portal. Portal CJF, Notícias, Tecnologia, 24 jun. 2019. Disponível em: https://www.cjf.jus.br/cjf/noticias/2019/06junho/na-era-da-inteligencia-artificial-conselho-da-justica-federal-lanca-plataformaque-interage-com-usuarios-no-portal. Acesso em: 6 ago. 2019.

NUNES, Dierle; MARQUES, Ana Luiza Pinto Coelho. Inteligência Artificial e Direito Processual: vieses algoritmos e os riscos de atribuição de função decisórias às máquinas. Revista de Processo, São Paulo, v. 285, p. 421-447, nov. 2018.

MIGALHAS. Projeto-piloto do Sócrates, programa de inteligência artificial do STJ, é esperado para agosto. [S.I.], 6 abr. 2019. Disponível em: https://www.migalhas.com.br/Quentes/17,MI299820,51045Projetopiloto+do+Socrates+programa+de+inteligencia+artificial+do+STJ. Acesso em: 6 ago. 2019.

SKAF, Paulo. Inovação no Judiciário Paulista. Jota, São Paulo, 8 abr. 2019. Disponível em: https://www.jota.info/opiniao-e-analise/artigos/inovacao-nojudiciario-paulista-08042019. Acesso em: 6 ago. 2019.

CONSULTOR JURÍDICO. STJ cria sistema de inteligência artificial para agilizar processos. [S.I.], 14 jun. 2018. Disponível em: https://www.conjur.com.br/2018jun-14/stj-cria-sistema-inteligencia-artificial-agilizar-processos. Acesso em: 2 ago. 2018.

TEIXEIRA, Matheus. STF investe em inteligência artificial para dar celeridade a processos. Jota, Tecnologia, [S.I.], 11 dez. 2018. Disponível: https://www.jota.info/coberturas-especiais/inova-e-acao/stf-aposta-inteligenciaartificial-celeridade-processos-11122018. Acesso: 2 ago. 2019. 
MINAS GERAIS. Tribunal de Justiça do Estado. TJMG utiliza inteligência artificial em julgamento virtual. Portal TJMG, Notícias, Belo Horizonte, 7 nov. 2018. Disponível em: https://www.tjmg.jus.br/portal-tjmg/noticias/tjmg-utiliza-inteligencia-artificialem-julgamento-virtual.htm\#.XcChotVKiUk. Acesso em: 3 ago. 2019.

Recebido em 27/08/2019.

Aceito em 01/10/2019. 